Nouvelles perspectives en sciences sociales

\title{
Evicted: Poverty and Profit in the American City, Matthew Desmond, New York, Crown Pulblishers, 2016
}

\section{Sylvie Lafrenière}

Volume 12, numéro 1, novembre 2016

URI : https://id.erudit.org/iderudit/1038381ar

DOI : https://doi.org/10.7202/1038381ar

Aller au sommaire du numéro

\section{Éditeur(s)}

Prise de parole

\section{ISSN}

1712-8307 (imprimé)

1918-7475 (numérique)

Découvrir la revue

Citer ce compte rendu

Lafrenière, S. (2016). Compte rendu de [Evicted: Poverty and Profit in the American City, Matthew Desmond, New York, Crown Publishers, 2016]. Nouvelles perspectives en sciences sociales, 12(1), 280-282.

https://doi.org/10.7202/1038381ar d'utilisation que vous pouvez consulter en ligne.

https://apropos.erudit.org/fr/usagers/politique-dutilisation/ 


\section{Evicted: Poverty and Profit in the American City}

Matthew Desmond, New York, Crown Publishers, 2016.

\section{PAR SYLVIE LAFRENIÈRE \\ Vancouver Island University}

Cet ouvrage de Matthew Desmond présente les résultats l'auteur habite dans les plus pauvres quartiers de Milwaukee dans l'état du Wisconsin, aux États-Unis, où il fréquente, afin de recueillir leurs histoires, des individus vivant dans une pauvreté extrême. Dans ce livre, Desmond s'intéresse particulièrement à l'expulsion, un phénomène qui, selon lui, a changé depuis le début du $\mathrm{XX}^{\mathrm{e}}$ siècle et qui est de plus en plus fréquent aux États-Unis.

Lauteur nous présente huit familles affectées par le processus d'expulsion. Il en montre les effets sur la famille immédiate (autant les adultes, souvent mères célibataires, que les enfants), la famille étendue (les parents, les frères et sœurs, souvent sollicités ou immédiatement touchés par l'expulsion de leurs proches) et les amis (auxquels on demande aussi de l'aide et qui sont, eux aussi, touchés directement).

En plus de suivre et de présenter les familles, Desmond nous fait comprendre le point de vue des propriétaires qui, eux, ont des comptes à rendre et doivent prendre de graves décisions concernant leurs biens et concernant les personnes à qui ils ont choisi de louer leurs logements. Ce faisant, l'auteur montre comment les décisions discriminantes des propriétaires peuvent représenter dans divers quartiers une des causes majeures de la ségrégation raciale et économique.

Le livre Evicted: Poverty and Profit in the American City fait donc plus que raconter des histoires : à travers les difficultés et les malheurs que subissent les acteurs qui sont dépeints dans 
l'ouvrage, l'auteur produit une image de la société contemporaine et de la place qu'y occupe la pauvreté, et ce, tout en examinant les systèmes d'aide sociale et les systèmes légaux avec lesquels les personnes démunies doivent composer, Desmond réussit à dépasser les histoires individuelles et personnelles pour développer une théorie du monde de la pauvreté.

Il présente, de plus, des perspectives intéressantes et cohérentes concernant les effets de la précarité du logement sur les communautés affectées. Par exemple, à cause de déplacements fréquents, les personnes qui habitent un quartier se connaissent très peu : ils se fréquentent peu, ne ressentent pas de solidarité les uns envers les autres, et ont peur d'intervenir dans les malheurs de leurs voisins de crainte d'enrager les propriétaires ou d'impliquer la police. L'investissement social dans la vie du quartier est donc affecté. Les déplacements fréquents font aussi en sorte qu'il y a moins d'intérêt pour l'investissement économique dans les maisons et les immeubles, ce qui mène au délabrement éventuel des logements. D’après Desmond, cet état de choses est différent de ce qui existait au début du $\mathrm{XX}^{\mathrm{e}}$ siècle quand des quartiers entiers pouvaient sortir pour empêcher l'expulsion d'une seule famille. Aujourd'hui, les rideaux sont fermés et le soutien mutuel est quasi inexistant.

Tout au long du livre, l'auteur nous fait vivre des moments déchirants, pour ensuite nous faire comprendre les éléments sociaux et systémiques qui rendent difficile la sortie de ce monde, les éléments qui servent le cercle vicieux de la pauvreté : la maladie qui mène à la toxicomanie; la toxicomanie qui mène à une cessation de travail; la cessation de travail qui mène à l'expulsion; l'expulsion qui rend la maladie plus pénible...

Desmond développe une théorie pour expliquer le développement de la ségrégation par quartier. Fort de cette théorie, il termine en proposant des solutions pour la réduction de la stigmatisation et de la criminalisation de la pauvreté.

Le livre se lit bien, l'auteur passant facilement entre le vécu des acteurs et une nouvelle théorie de la société et de la pauvreté, une théorie qui fait le lien entre le microsociologique et le macroso- 
$282 \mid$ NPSS, VOLUME 12, NUMÉRO 1, 2016

ciologique. Il présente un excellent exposé de la vie dans une pauvreté extrême et des systèmes de divers types qui aident ou qui nuisent aux personnes qui sont dans le besoin. 